\section{AESTHETICS INPUT OF MURALS AND ENVIRONMENTAL SCULPTURES IN THE BUILT \\ CITY OF LAGOS}

'Oyinloye Michael Abiodun, ${ }^{2}$ Ijisakin Eyitayo Tolulope, ${ }^{3}$ Oladesu Johnson Olarinde and

Siyanbola Afeez Babatunde

Department of Fine and Applied Arts, Olabisi Onabanjo University, Ago-Iwoye, Nigeria

${ }^{2}$ Department of Fine and Applied Arts, Obafemi Awolowo University, Ile-Ife, Nigeria.

E-mail: michael.oyinloye@oouagoiwoye.edu.ng; abbeymyke@yahoo.com

\section{ABSTRACT}

There is a conscious effort to improve aesthetics, using visual arts to beautify the city of Lagos like other cities of the world. This study examines aesthetic characteristics of selected visual artworks in form of sculptures and murals erected at strategic places in the city of Lagos with a view to understand their aesthetic functions and socio-cultural relevance in the environment. Using qualitative art historian method, the study employed field investigation for getting useful information for the study; while photograph of selected works were critically analysed, using symbolic reality, unity of

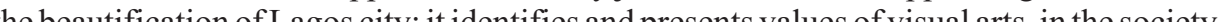

Keywords: Visual Arts, Aesthetics appraisal, Murals and Environmental Sculptures.

Accepted Date: 27 April, 2020

\section{INTRODUCTION}

The term 'aesthetic' is derived from the Greek word 'aesthesis', meaning sensory perception (Magrane, 2012). It is a branch of philosophy that deals with nature of art, beauty and taste encompassing the creation or appreciation of beauty. In its more technical epistemological perspective, it is defined as the study of sensory emotional value, or judgment of sentiment or taste (Magrane, 2012). In other words, aesthetics involves how artists agine, create and perform works of art. It may further be explained as what happens in Artists' minds, when they see and hear words; and the ways they interpret them to the society. It is also the study of artist's feelings about art, how art can affects moods, beliefs, and attitude towards life. Baumgarten (2007) observes aesthetics as emphasizing the sensory, rather than intellectual nature of judgments. Therefore, judgment of aesthetic values relies on the ability to discriminate at sensory level. Aesthetic value could be viewed a to (positive value) or displeasure (negative value) when

appreciated or experienced (Magrane, 2012). Here, emphasis on pleasure or displeasure has always appeared to pose a challenge to the objectivity of aesthetic values and aesthetic judgments. In thi regard, one tends to weigh the dexterity of the artist on one side, and look at the shortcomings or inadequacies of a particular work of art on the othe side. Plato and Meskin (2013) further argue that aesthetic value is a matter of personal preference or like; therefore, what is pleasurable to someone may . Alato an Meskin (2013), aesthetic value is the worth of a artwork or natural object that gives pleasurable appreciation and satisfied experience to the viewe This overwhelming phenomenon is created in an encounter with work of art. The enjoyment derived, lingers on for as much time as one can find another work of art that is comparable to the former. In the same vein, aesthetic value can be termed as the worth of artwork, judging by the lasting satisfaction anes to the end user. In this regard, an aesthetic appreciation is needed to trigger a positive appreciate visual artworks mounted or displayed in the environment. Kant (2001) on the other hand, considers aesthetic judgment as 'subjective', he believes it is rooted in pleasure or displeasure; Kant argues that, judgment of beauty involves a claim to universality acceptance. He maintains that, when a natural or manmade object merits aesthetic quality, many people will reckon with the beauty embedded in it, there will not be two way judgments. In his view, the judgment that something is beautiful (aesthetically valuable) involves the claim, that the claim, th ther people should agree with the judgment.

Summarily, to know aesthetically pleasing objects, one must be able to identify the presence of aesthetic features of an art object. These include: presence of symbolic reality, unity of fascination, and aesthetics appraisal (Markovic, 2012). It is when these features are present that one would be able to determine the aesthetic values in a visual work of art. It is against this backdrop, that, this study examines aesthetic characteristics of selected environmental sculptures, graphic signs and murals thategic public spaces in the city of Lagos. Using the symbolic features in the environment, the study uses elements and principles of arts to determine the aesthetic values and functions of the visual art works in the city of Lagos.

Methodology

Data for this study depended significantly on field investigation. Unstructured interviews were conducted with passers-by, using oral/interactive format. Field inforstion and photographs of visual art works in different locations in Lagos city were taken, out of which ten (10) were selected for critical analysis. Secondary data were collected from textbooks, journal publications, and internet sources. Data collected were analysed using qualitative approach of art historical study.

\section{Rationale for appraisa}

To properly appreciate the aesthetic values of the visual arts in Lagos city, the works were categorised into two: murals and environmental sculptures. Under murals, there are four plates (plates $1-4$ ), while plates $5-10$ are sculptural works. The study found out that, all the environmental arts pieces displayed within Lagos city were sponsored by the Lagos government; while Terra Kulture, one of the leading art, culture, lifestyle, and educational centre was contacted to recommend artists who handled the projects. The study also observed that, the mural and sculptural works were done by artists who acquired the knowledge through formal system of training. Mr. Lanre Ajayi, the General Manager of terra Kulture Victoria Island, Lagos provided information on the artists were commissioned by Lagos State Government to produce the works. The study dwelt on personal 'on-site' viewing/observation, descriptive study and interaction with resident around the locations of the displayed art works for data collection, which were later analysed. The jure works based on the the principles and elements of visual arts.

\section{Beginning of beautification in Lagos city}

According to oral tradition, a lot of art works were commissioned at the independence period, when Lagos was the capital of Nigeria. The works were to showcase the cultural diversity of the country, to serve as symbols of liberation from colonial rule for most national establishments and for the preservation of relics, civilization, culture and important traditions of a rapid changing society (Oduwaye, 2006). This was the genesis of public or environmental art in Lagos city. Going through the entire city of Lagos, there are quite a number of beautiful environmental art works displayed all over the city, the reason for this is not far to seek, because of the different ethnic groups residing in the city. For instance, there were statues of the Nigerian fallen soldiers (Soja Idumota) who fought the civil war in the late $60 \mathrm{~s}$. Their statues were erected at Idumota, Lagos Island in the 80s and were moved to Dordon barrack in the 1990s. Another look at Lagos environment gives a picture of a city playing host to the entire Nigerian society represented by different groups of people from all walks of life (Government of Nigeria, 2007; City Mayor, 2010). In addition, Lagos city remains the commercial nerve centre of Nigeria where most people has come for survival (Oduwaye, 2006).

The study identifies in the city of Lagos, beautiful and valuable mural paintings adorning different places such as bridges, bus stops, road junctions and public buildings (Plates 1,2,3 and 4). There are also monumental sculptures of heroes and heroines erected in Lagos to beautify the environment and keep memories of the historic deeds alive (Plates 5 and 8). The study also observes beautifu landscapes with horticultural design at 
roundabouts, notable junctions, and public spheres and modern architectural designs which spice-up the aesthetic values in the city of Lagos. These aesthetic substances are part of the conscious efforts being made to recreate aesthetics order in the city of Lagos. Beyond beautification of the city scape, most of the art works were identified to be symbolic in nature, typifying socio-cultural figure in history or object of cultural relevance. While depicting these works, elements and principles of art were also put into consideration by the artists to complement their functions as environmental art.

\section{Environmental arts in Lagos city}

The display of art works in public spaces started as a concern to integrate socio-cultural and ecological approaches to develop the environment, and makes it aesthetically habitable for human being (Magrane, 2012). In this direction, visual art has been employed in the Lagos city as a measure to create aesthetically pleasing environment while addressing social and political issues relating to natural and physical environment. Elements of art such as line, texture, forms and colours are put into consideration to recreate natural and manmade objects to fashion out beautiful landscapes in Lagos city. The making of murals and sculptural art in the public spaces show how citizens should think, get connected, and respond to the society socially, philosophically, economically and spiritually (Baumgarten, 2007). It is expected that Lagos inhabitants understand messages conveyed by the environmental arts sited within the city. However, this response depends on the subject and theme of visual art in question as displayed by the artists. Artist produces work of arts that have strong social and cultural values worthy to be displayed in the public space. The major purpose of executing artwork in the public spaces in Lagos is for beautification, and also to serve as a reservoir of people's cultural history, and to equally address pertinent issues in the society. For instance, some of the enviroment paintings in Lagos address societal vices and youthful misconduct (Plates 3, 4 and 10). For instance, plates 3 and 4 are murals conveying messages against drug abuse and street hawking. The figurative illustrations convey symbolic images of reality, addressing a purpose. The colour scheme of the murals also suggests an arrangement of harmonious hues which are quite fascinating

well as attractive. Also the visual concept of mura could add aesthetics values to public places such as hospitals, bus stops and motor parks. Though, these works are pleasant to behold at these places, they could also serve as precautionary measure against evil deeds for youth and the society at large. Although works of art are seen as adding aesthetic values to Lagos city, they also carry messages meant to be remembed and preserved for tim may be for histical knowledge which is at tines be con to from time to be consulted from time to time. These aesthetic objects at times perform duties greater than spoken words. These works of art can be used to create awareness about issues and provoke necessary public response to environmental insecurity, risk and ways of achieving an egalitarian society. Through most of these works in Lagos city, a lot of people have been able to find solutions to issues in lives. For instance, 'empowerment' (Plate 10), at the Yaba roundabout is a pointer to the fact that education is a life insurance that is capable of giving life meal ticket to youths. It is a sculptura work rendered in beautiful shapes after the order of classical art proportion. It depicts figures full of life, mood and emotion. The subject-matter is clearly depicted, reminding one of the benefits of education in the society. Generally speaking, this study observ State, where ans, petty traders of all sorts and transpor, atisans, petty ren 2,3,4 and 8 . Moat and quiet environment (Plates ( the past are now decorated with horticultural landscaping with beautiful walkways. These have aesthetically acceptable to passers-by. This effort and foresightedness of the Ministry of Environment and Works in the State is commendable, because it brings about aesthetic appraisal. The study observe among others, that surfaces of columns and available plains under the bridges in Lagos city have now been embellished with different works of art, with thematic focus on diverse kinds of subject-matters ranging from historical matters, monumental sculpture, sporting activities, health matters, and presentation of sociocultural activities. The type of spaces available under the bridges, also determines the type of subject matter to be painted on them. Pedestrians movement is also factored into what determines the positioning of environmental art at a particular place in the city of Lagos. The study observes, essence is to mount an art work in a place where it will gain public viewing, and acceptability, giving credence to unity of fascination and aesthetic appreciation.

The paintings on wall of bridges are executed at the bus stop domain, where many pass on daily basis. This in a way has added beautiful appearances and warm reception to the public space under the bridge at the popular Ojuelegba bus stop. Such public spaces with environmental art include Obalende, Ikeja, Lekki Peninsula, Ojota, Ikorodu, Maryland, Tinubu Square, Ojodu Berger among others. The works in these spaces attract people, who pose to take photographs with the painted background in order to add beautiful background to their photographs. It was observed that, most passers-by cannot resist gazing at the beautiful and precautionary paintings for aesthetic pleasure. It is such an aesthetic experience that viewers wish, it last with them for as long as they would find another beautiful piece of art that could match with the current one. Aesthetic expression is the representational part of the contents of visual artwork, and the attention it derived from people (Winston and Cupchick, 1992). By this position, it is on the content that can be misunderstood) by the people, but its physical appearance must be appealing and attractive, to the extent that, it keeps the viewer's ever gazing at it. The memory of expression of forms, lines, colours and draughtmanship they would want to keep forever. The aesthetics display of visual art works, at the popular Tinubu Square, is an improved horticultural and visual art display in the Lagos Island. The first artistic work that catches one's attention is the environmental sculpture: "Wings of Liberty" which centrally placed in the square. It is a sculptural fountain produced with fibre glass, the wing of liberty probably recalls the freedom of Lagos and entire Nigeria from Colonial rule at independence in 1960. The subject is semi-realistic in nature; it is a representation of birds' wings that can be discerned, while the real birds' heads were not actually depicted. The sculptural piece is a symbol of freedom and liberty produced with the combination of unity, forms and attraction wo satisfy aesthetics pleasure.
Tinubu Square has become a recreational place for relaxation, and enjoyment, since the garden was rebuilt in the 90s. The inputs of environmental art and landscape designs have made the location to become an attractive centre for commerce, commuters and passers-by. The reconstruction of Tinubu Square with the embllishment of aesthetic forms has added values that are fascinating to people on daily basis. The study observed, commuters sits comfortably and relax within the fenced square for as much as time permits individual, before they would proceed on their daily activities. Aesthetics content of the works of art at Tinubu Square makes the place a sight to behold you cannot pass-by without catching a glimpse of the beautiful sculptural pieces mounted in the square. The coolness of breeze, from the water fountain is also splendid at the square. The architectural landscaping of the square, obeys the aesthetic order and principles of design. The sculptural pieces are super realistic in nature that keeps one wondering, if they are actually human being or art pieces. One could hardly pass by the Tinubu Square, without being fascinated to the aesthetic happenings at the place. You will always want to have a better glance of the sculptural pieces, mounted within the fenced square. The beauty of the creative art works, combined with the horticultural design of the flowers as well as the water fountain, will certainly arrest one's focus. It is really an aesthetic experience, which enhances the atmosphere to become wonderful scene to behold. In view of this, Ognjenovic (1997) argues that aesthetic experience as a special kind of object relationship with man. In this case, a particular object strongly engages the subject's mind, overshadowing all other objects and events. It is not a matter of I do, or do not like art but of pronounced aesthetic values that is pleasurable to the environment. Also at Tinubu's square, is a monumental cenotaph in memory of late madam Efunroye Tinubu (Plate 8), after whose the square was name. It is another sculptural piece that adds value to the aesthetics of the environment. Madan Tinubu was an irrepressible opponent of the slave trade and British Colonial Government. She was an Icon of enterprises and leadership, her immense wealth and nationalism earned her prestigious title of Iyalode of Egba land till her death in 1887. Other aesthetics input in the area, is the figurative sculptural expression of one time popular blind 
drummer called 'Kokoro' the blind drummer and a female dancer. Kokoro was a freelance 'sakara' drum player and singer. He earned his living by going from place to place to entertain people in Lagos Island in the 1970s. This study also, considered the figurative sculpture at centre of Lagos city in Maryland as worthy of symbolic eality. It is a revelation of rich culture and diverse coup of a reope in group of people in Nigeria. Here are podiums with figures dressed in traditional attires of Hausa, lbo, Yoruba, Efik, Tiv etc., which portray different culture in Nigeria. The sculptural pieces are so naturalistic in rendition without missing any mark. It is really an aesthetic sight to behold, as it welcomes 'Lagosians' and foreigners, as they go in and out Lagos Mainland. The images were strategically placed at the cross junction of Maryland roundabout, going to Ikeja. The finesse of the sculptural pieces encompasses painting of the figural objects with gold colour; the podiums were painted white and black with rectangular marble base. Also depicted on the podium are indigenous symbols, and motifs, notable with different people of Nigeria. Here, the excellent artistic mastery of materials display by the artists, the work is the zenith of aesthetic values capable of attracting attention of passers-by. It is also an added beauty to Maryland junction and environs. As bserved by passers-by, such objects of cultural Undage are idealto renitional identity. Under the biinge at Ojuelegba, are some visual expressions of aesthetic values rendered with colourful paints. Parts of the sceneries are figurative mural paintings which are visual representation of Oba Rilwan Akiolu. There is also mural painting of the highlife musician, Alhaji Fatai Rolling Dollars (Plate 2). The study observes that, the idea behind the mural painting is to make known to the public, some important personalities who are native of Lagos. Apart from the primary goal of passing information to the public, this mural conspicuously displays aesthetic appraisal on the concrete pillars of bridge in the city of Lagos.

At the Lekki Penisula roundabout is, "Virtue of Life - Courage" (Plate 9) which is made of collection of junk metal materials put together, to create a work of art. A critical look at this art piece, reveals how creative and resourceful, the artist has been in putting together these 'waste metal material' to create beautiful pieces of artwork capable of by them. The artist, Segun Aiyesan sees creativity, beauty and recreation, out of what other people considered junk, waste and not useful materials. The artist turns waste to wealth, by picking waste objects and materials from the environment. $\mathrm{He}$ rearranged them in the order of unity of purpose, in order to form aesthetics object for appraisal. This process is what Oguntona (1986), describes as art pectibes as at t which embraces imagination, creativity, aesthetics an functions for particular purpose. The work is an act of mental tasking, involving creativity, in orders to rearrange forms to fascinate, and be aesthetically pleasing as environmental sculpture. The title suggests that, it takes courageous minds of the crew of Artists from the Universal Studio, Iganmu, Lagos led by Segun Aiyesan to execute such magnificent and aesthetic construction work. The work is a juxtaposition of graphics, The work is a juxtaposition of graphics, three dimners order to put experimental sculpture together. The work is balance of forms, textures and arrangement of shapes that gave birth to the inspirational maste piece. Empowerment (plate 10) is a fibre glas work mounted to create environmental beautify Yaba roundabout in the Lagos Mainland. This sculptural piece is a depiction of text book forms. On it are some human figures seated, while others are standing. At the top, there is a standing figure thearing actente wearing acade behin this sculptural work is to further impress the value of education in the heart of Nigerian youths. The Yaba roundabout is a popular open space, where many people daily go about their businesses. This thought provoking artwork can be seen as performing aesthetics function, as well as sending useful messages to the society. The gigantic sculptural piece was made at Iponri studio, Lagos, led by Abu Jinna. The human forms are clearly depicted and well represented in the order of the depicted and wer of the classical European art. Other inanimate objects such as books can be said to be idealized. Perhaps the emphasis of blowing the books out of proportion is to make education subject of concern to everyone in the society. Plate 6 is the statue of Eyo masquerade in Lagos Island. The Eyo masquerade is so popular in Lagos city, such that the cultural history of Lagos will remain incomplete without Eyo masquerade. Eyo is cultural festival restricted to the Lagos Island It is a socio-cultural identity of Lagos natives. Whenever the occasion arises for the Eyo masquerade to entertain the people of Lagos, it is a whole day affair in Lagos Island. The Eyo masquerade, depict shapes as of the Cubist stylistic art. Francis Donedu, the artist who derives pleasure in making metal construction by using basic shapes. The Eyo figures are depicted in the classical art style but the forms are reduced to basic sha remind one of Picasso and Braque. There is also Agba Meta (Three Elders), are statues (plate 5) at Ojodu-Berger. These are traditional white-cap chiefs of Lagos. They are also socio-cultural figures synonymous to the Lagos traditions. White cap and wrapper is the dress code for high chiefs in Lagos. The white cap is shown to flow to the back of the left shoulder of the chief. Wearing of protruding white-cap in Lagos is significant and also symbolic to high Chiefs in Lagos. These three figurative scut of Lagos city. For over a decade when these statues were unvelled, they have become a symbolic identity to Lagos city. The hands expression, as shown by these figures, is salutation, agreemen and unity of purpose. The white colour connotes the aquatic splendor of Lagos city. The sculptural pieces are super depiction of human forms by Biodun Shodeinde (Sculptor). The hands, legs and other parts of the body are well-structured by

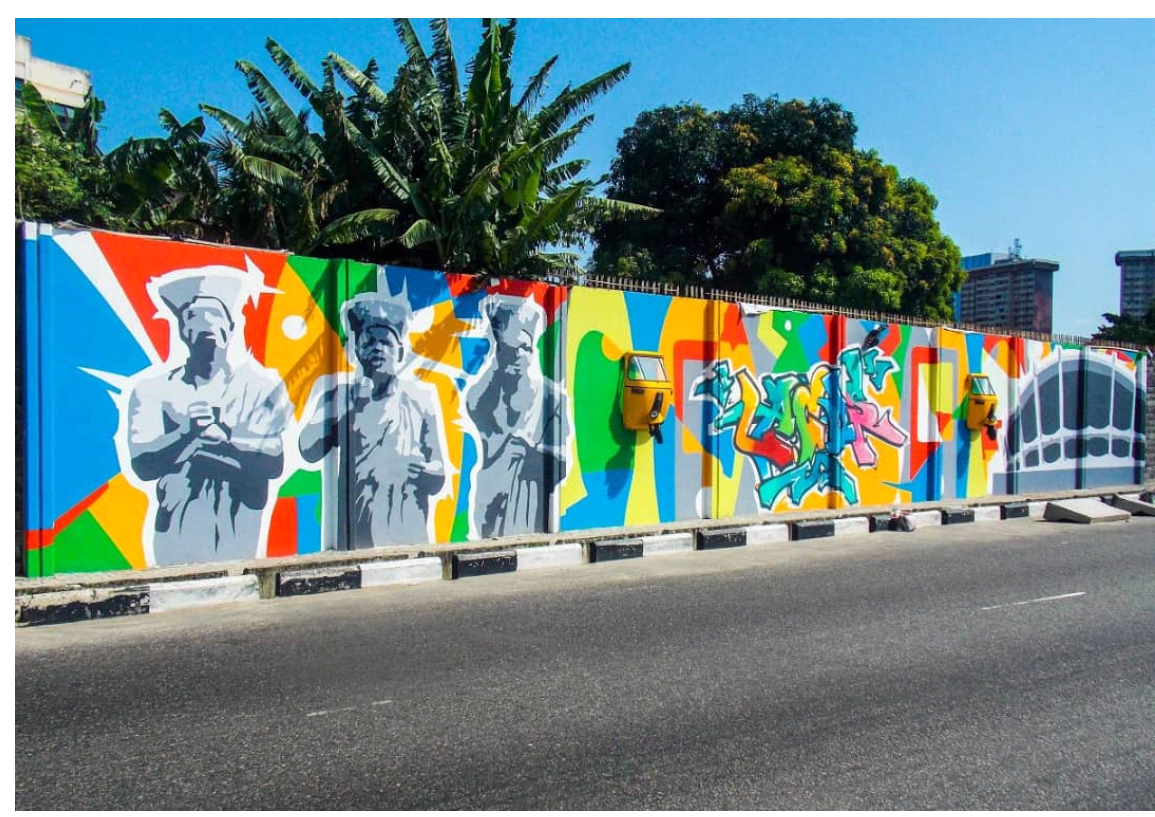

Plate: 1

Medium: Location:

Artist: Osa 7 professional artists. They wear facial expression that connotes joy and cheerfulness in the mood of celebration. The wrappers drape excellently suggesting easy movement of the legs and hands. There is no doubt that the statues exhibit classical art forms of beautification at the entrance to Lagos city. Community, (Plate 7), is a group of wooden culpture erected at Ile-Zik roundabout, which is can e hat gives a rhythmic visual flow that calch a then of passers-by. Each wooden object Also Also the cylindrically arranged abstract shapes formed a circular base for the work. The art work depicts togetherness of Lagosians living in unity, love, harmony. The work is a symbolic impact of

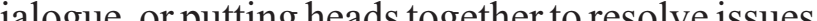
the Artist, Abolore Sobayo in Lagos on the objects. He also inscribed symos and motifs that are peculiar to Lagos State on these mese scistural pieces. The art work was erected in 2017 as enverate the Oth anniversary of Lagos State. 


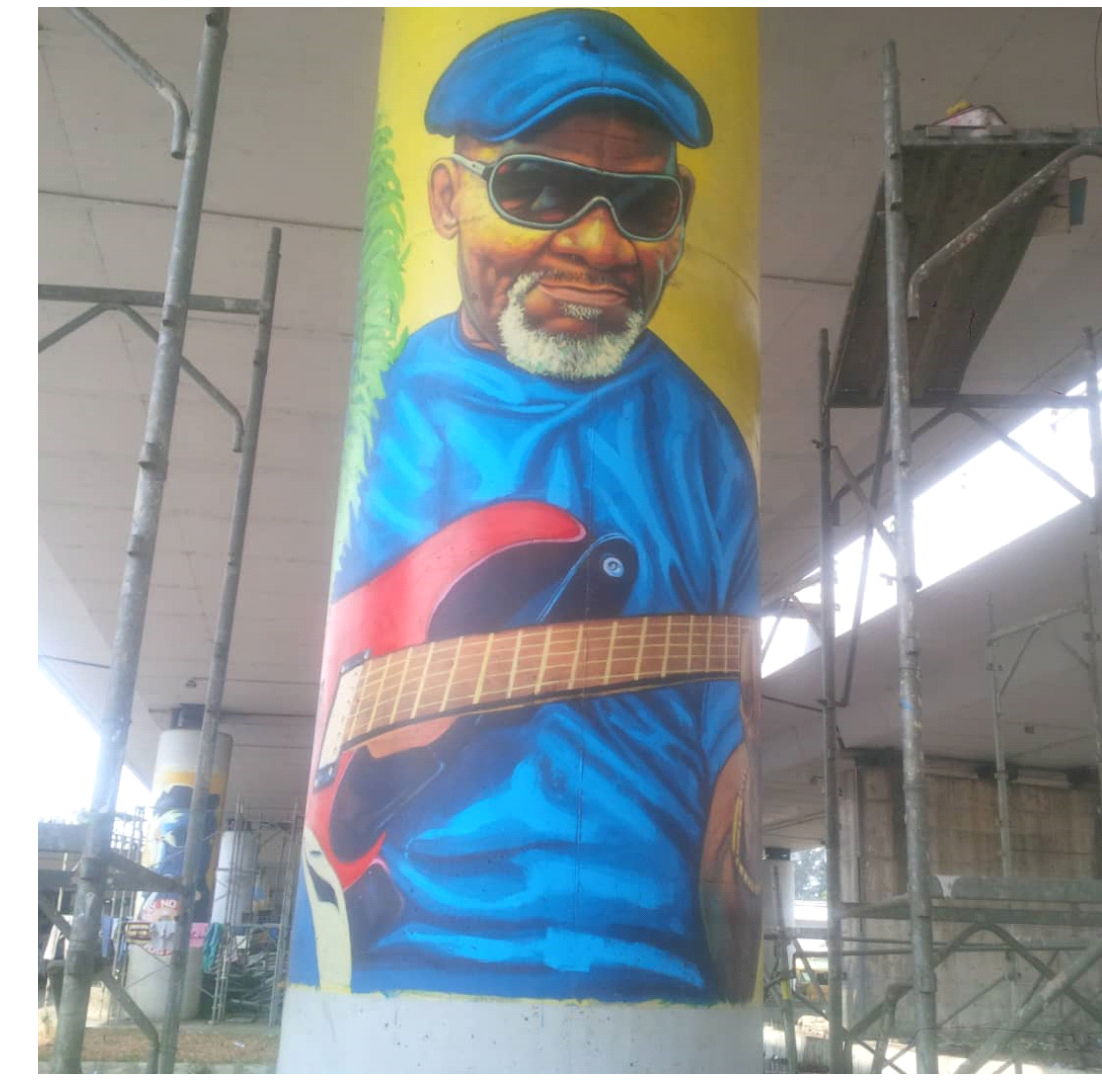

Plate: 2 Title: Fatai Rolling Dollar (Highlife Musician) Enamel paint Medium:

Oil paint on Concrete Location: Ojuelegba, Lagos. Artist: Peju Alatise

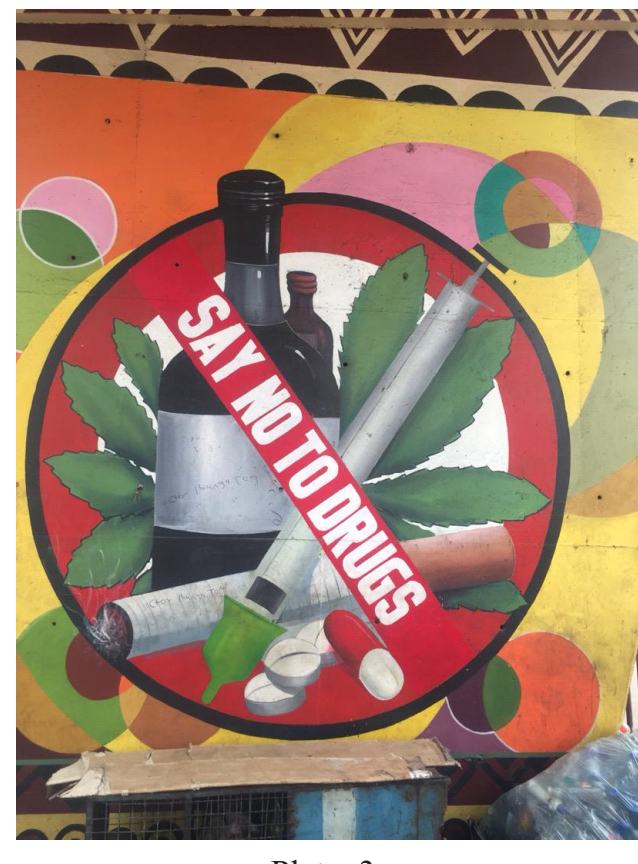

Plate: 3

Title: Say NO to Drug

Medium: Oil paint on Concrete

Location: Ojuelegba, Lagos.

Artist: Peju Alatise

A

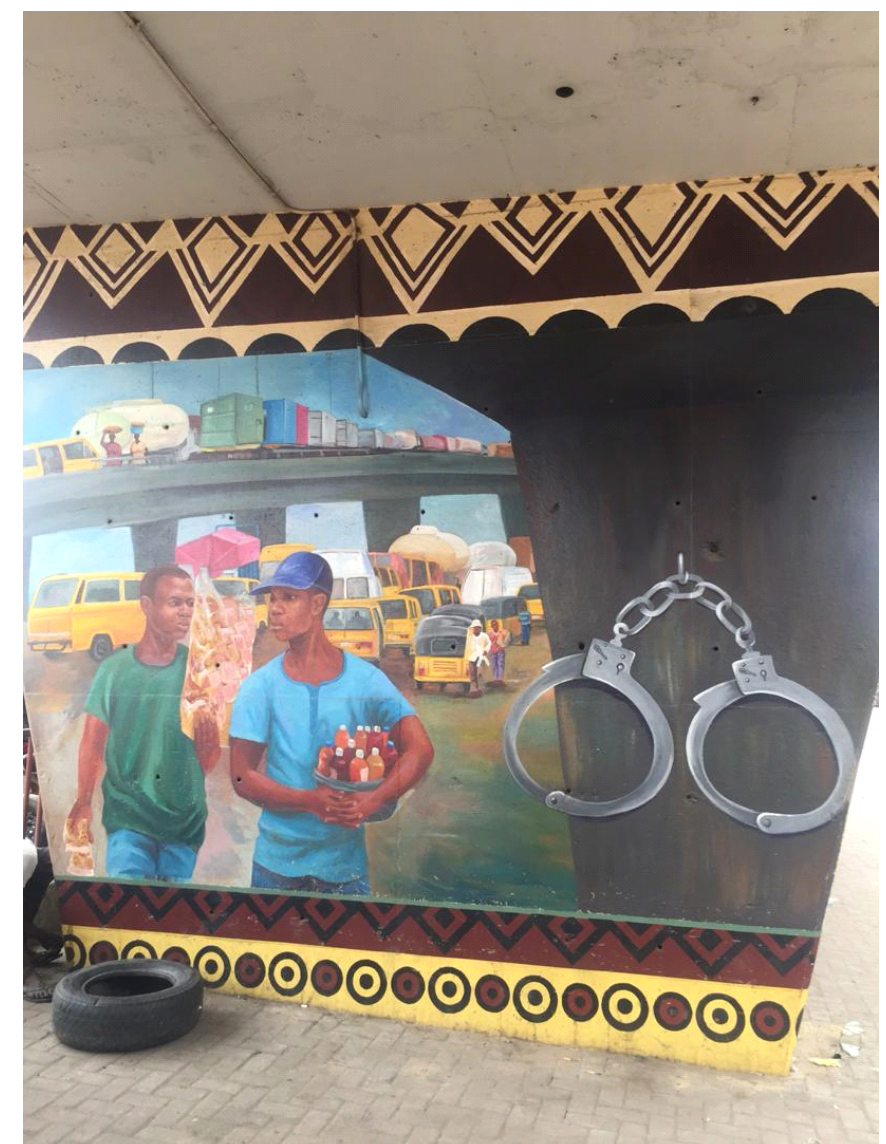

Plate: 4

Title: Street Hawking

Medium: Oil paint on Concrete

Artist: Peju Alatise

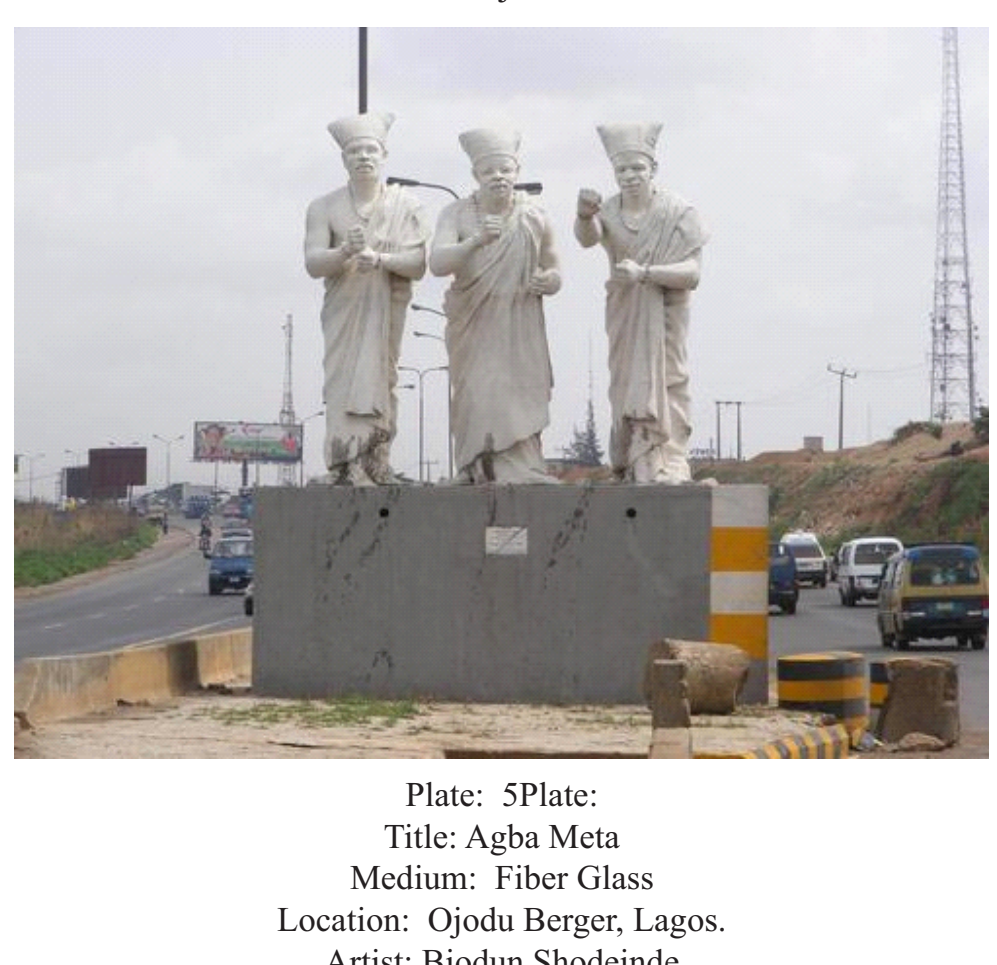

Lacation: Ojodu Berger, Lagos.

Artist: Biodun Shodeinde

JSN P-ISSN 2536-6904, E-ISSN 2705-2761 African Journal of Science \& Nature Vol. 10, 7-18 (2020) 


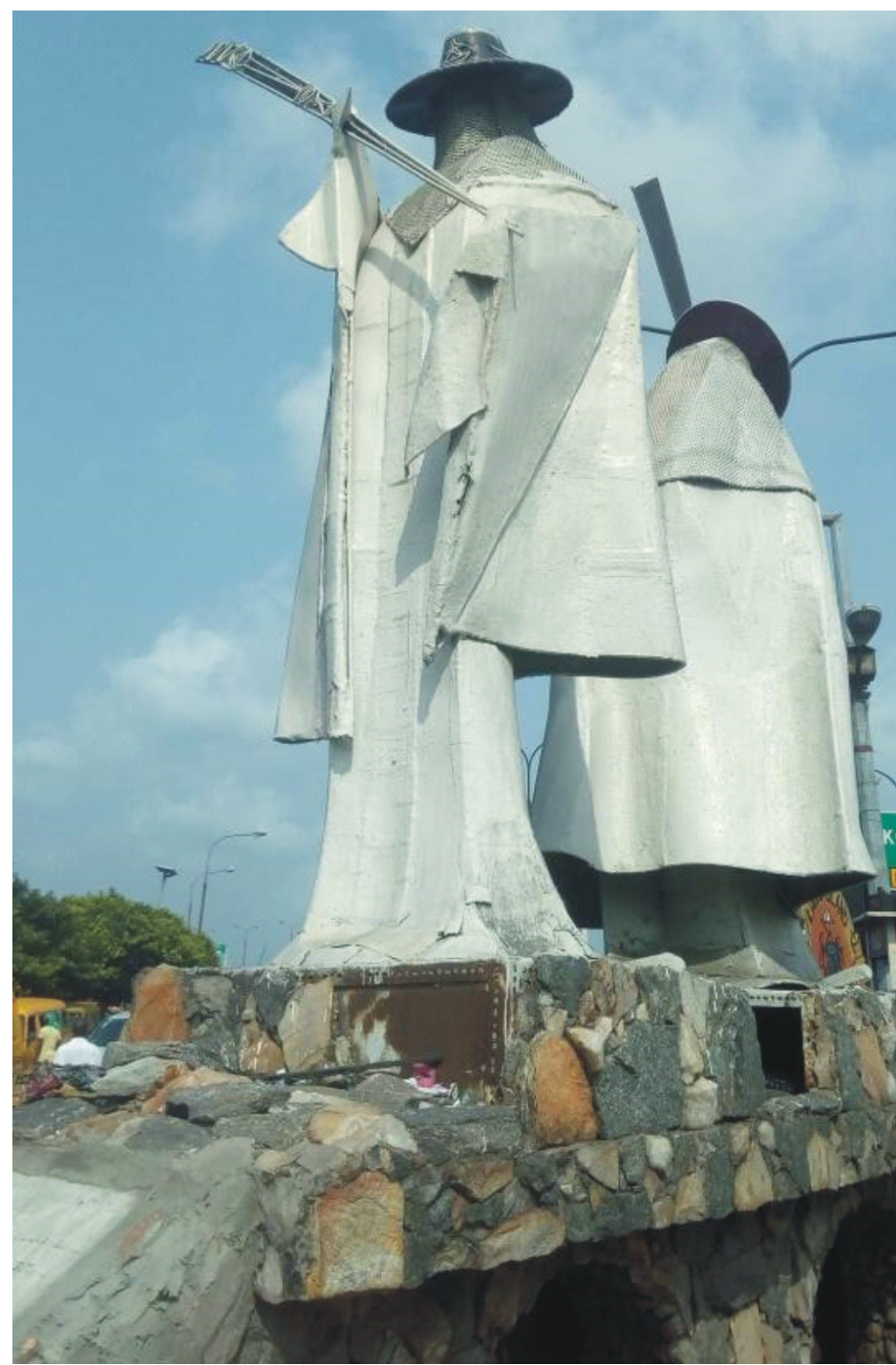

Plate 6:

Title: Eyo Masquerades

Medim. Metal Construction

Location. Lekki Penisula Lagos,

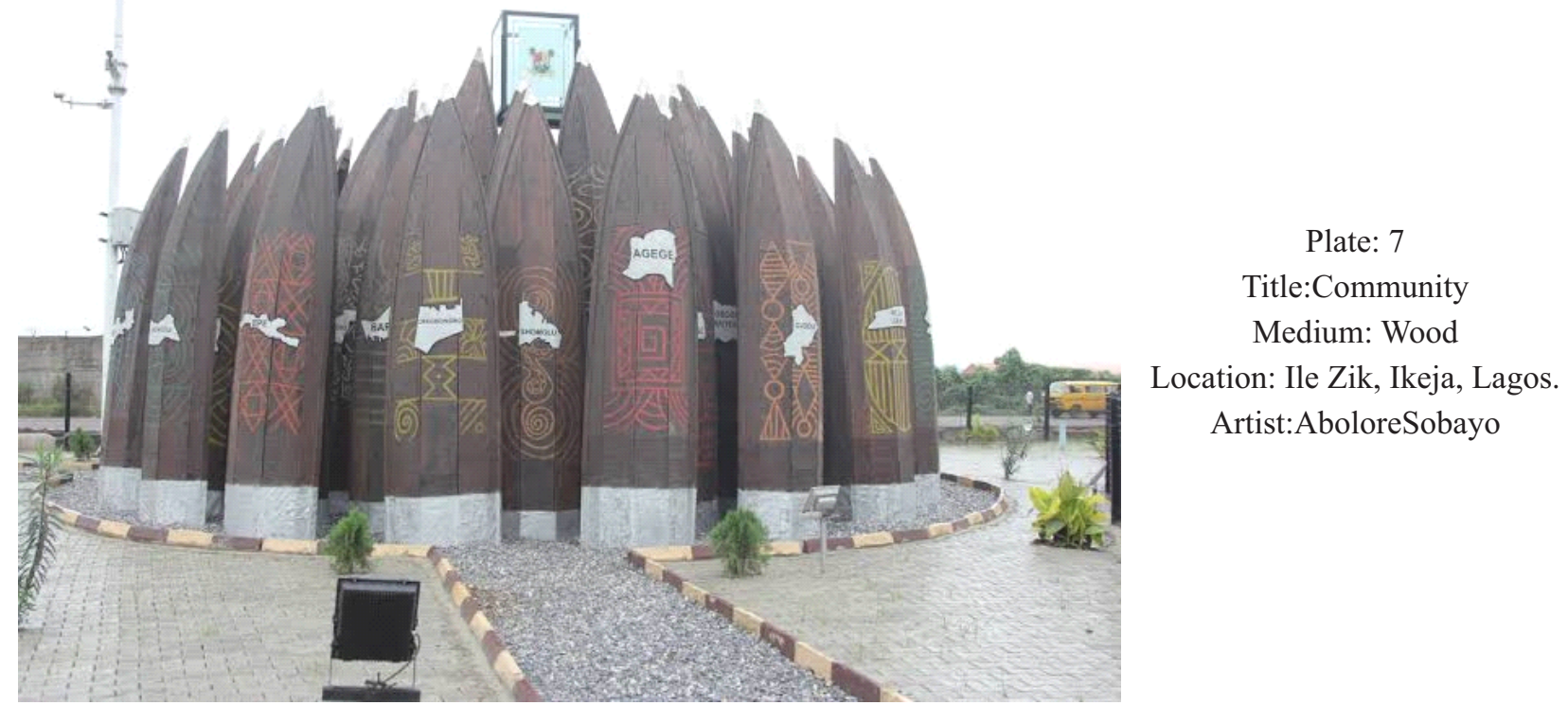

Ass,

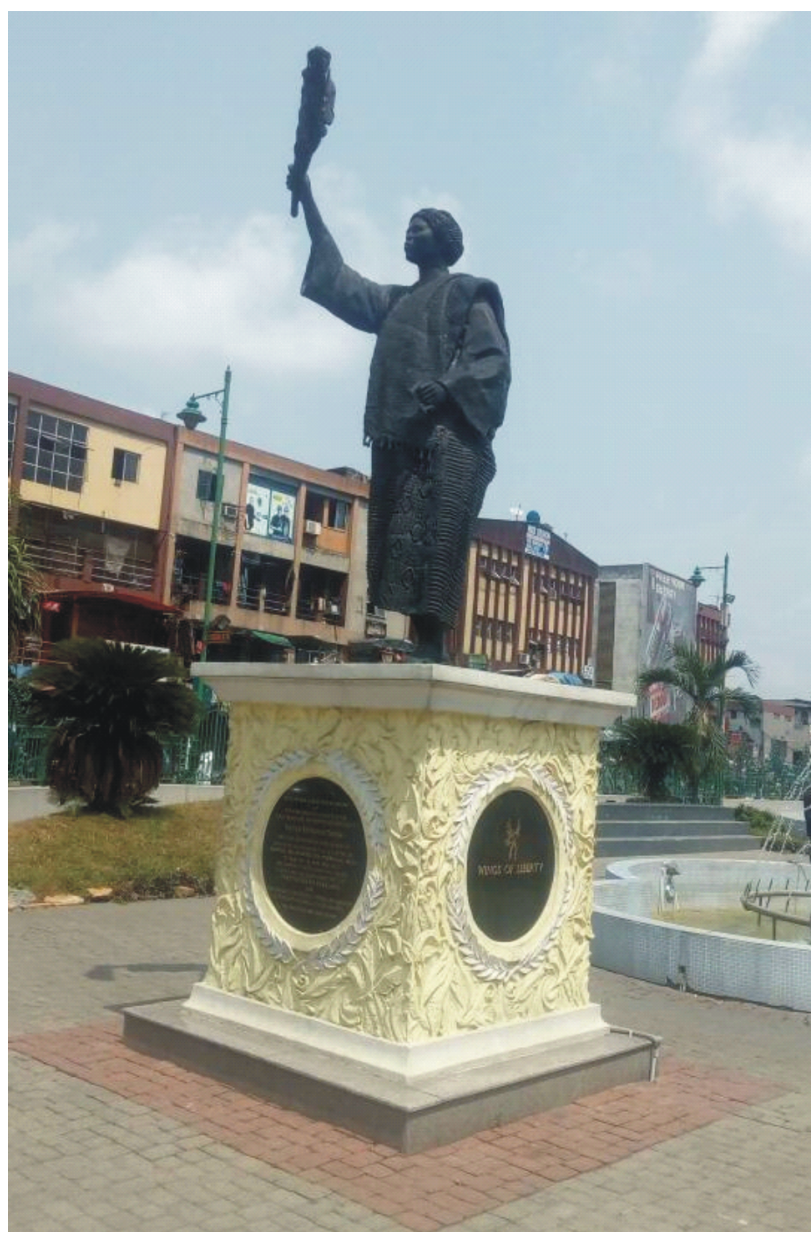

Plate: 8

Title:Late Madam EfunroyeTinubu

Medium: Fibre glass

Location: Tinubu Square, Lagos Island, Lagos.

Artist: Unknown

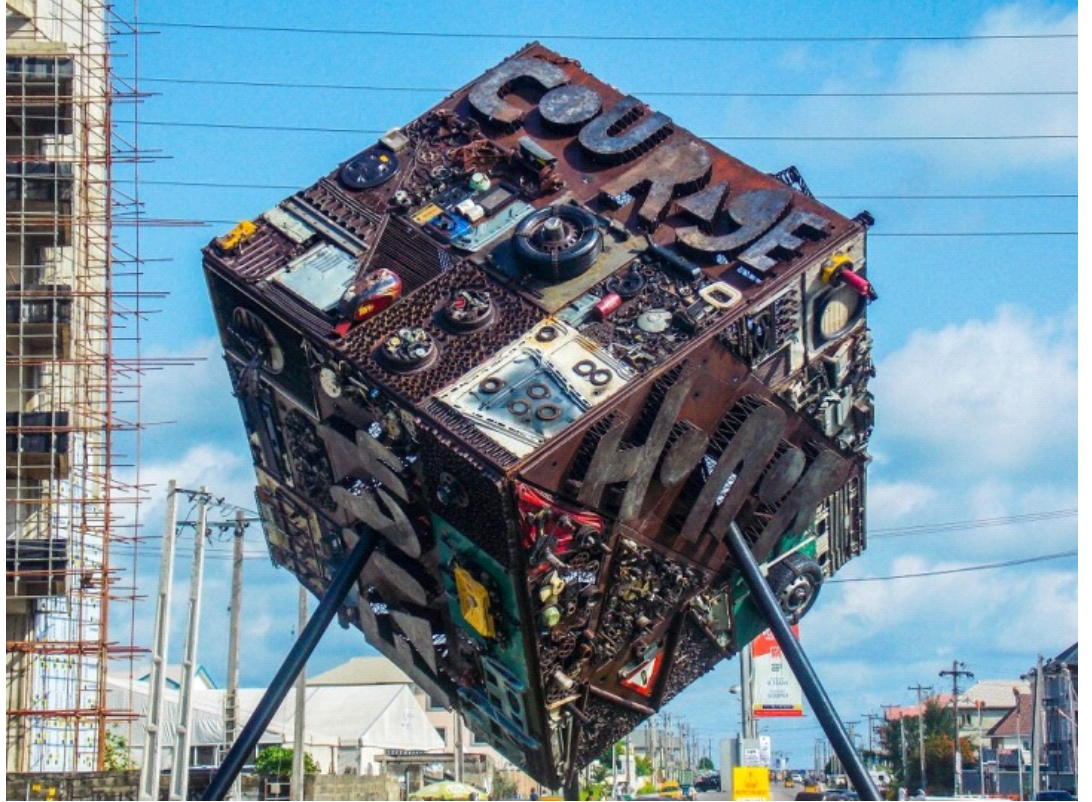

Plate: 9

Title:Virtue of Life

Medium:Metal Junk

Location:Lekki Round-about, Lagos

Artists: SegunAiyesan (Universal Studio) 


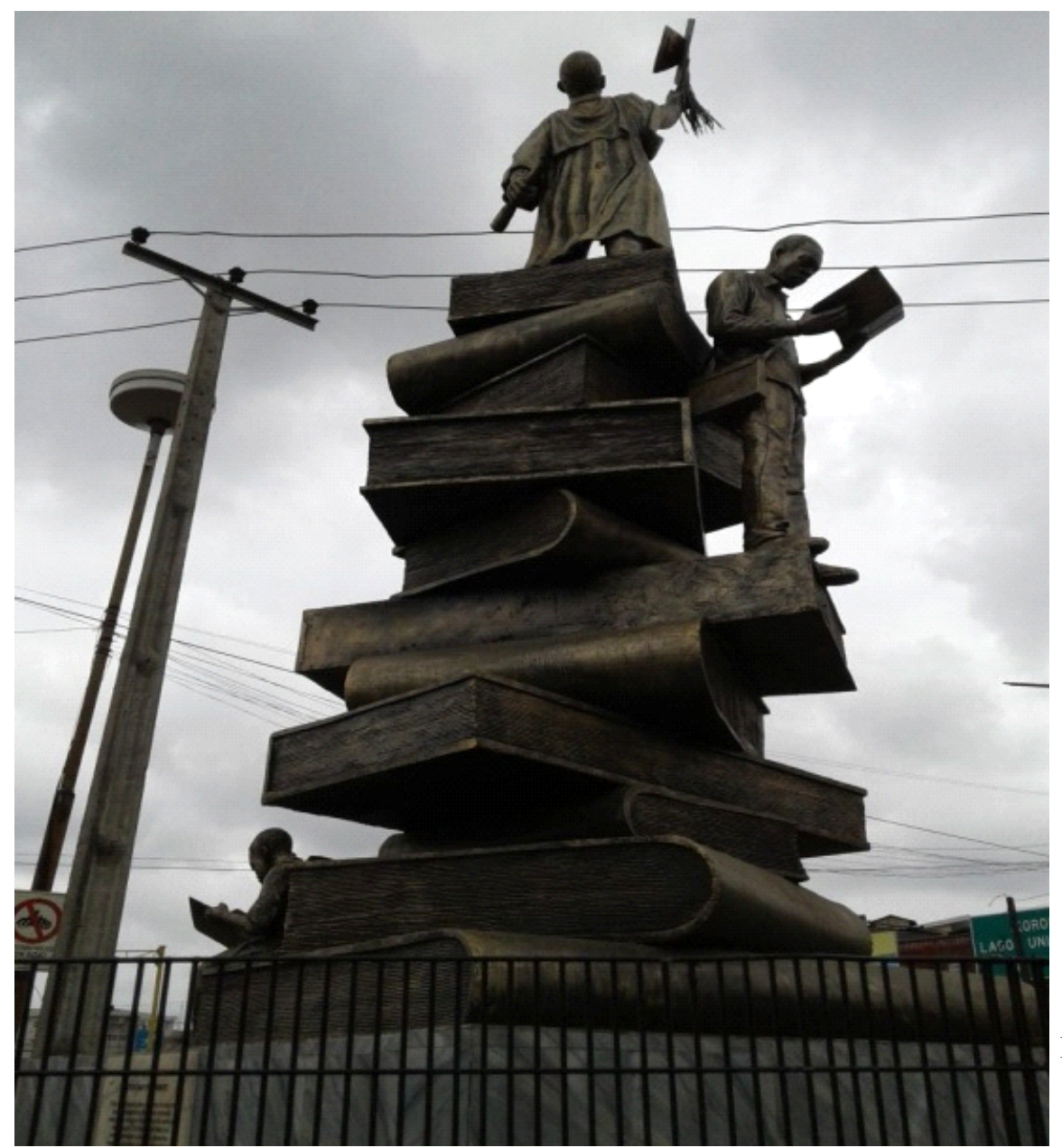

Plate: 10

Title: Empowermen

Medium: Fibre glass

Location: Yaba Round-about, Lagos.

Artists: Abu Jinna and group

Conclusion

The display of art works in public spaces started as a concern to integrate socio-cultural and ecological approaches to develop the environment, and makes it aesthetically habitable for human being (Magrane, 2012). In this direction, visual art has been employed in Lagos city as a measure to create aesthetically pleasing environment while addressing social and political issues to recreate natural and manmade objects to fashion out beautiful landscapes in Lagos city. The study also highlighted different places in Lagos city that are decorated with monumental artworks in order to city's socio-cultural and artistic values. This en inproved the level of visul literacy within Lagos city, because the study found out that, most of the art works were sponsored the Lagos State government. This in no some measure has made Lagos a beautiful city to behold

\section{Conclusion}

The display of art works in public spaces started as a concern to integrate socio-cultural and ecological approaches to develop the environment, and makes it aesthetically habitable for human being (Magrane, 2012). In this direction, visual art has been employed in Lagos city as a measure to create aesthetically pleasing environment while addressing social and political issues to recreate natural and manmade objects to fashion out beautiful landscapes in Lagos city. The study also highlighted different places in Lagos city th also Lagos city that are decorated with monumental artworks in order to preserve the city's socio-cultural and artistic values This endeavor by the Lagos Government can be said to have improved the level of visual literacy within Lagos city, because the study found out that most of the art works were sponsored the Lagos State government. This in no some measure has made Lagos a beautiful city to behold

\section{REFERENCES}

Baumgarten, A. (2007). Aesthetic Latin-German edition translated and edited by Mirbach D., hamburg, Verlag, M.

City Mayors.com (2010). World's fastest growing cities and urban areas from $2006-$ 2020. Retrieved on $10^{\text {th }}$ March, 2010 from www.citymayors.com/ statistics/urban-growth1.html

Government of Nigeria, (2007). Lagos State claim on the provisional result of the 2006 Census is Uniform. National Population Commission ( 8 February, 2007). Retrieved on $10^{\text {th }}$ $\mathrm{M} \mathrm{a} \mathrm{r} \mathrm{c} \mathrm{h,} 2010$ fro m www.population.gov.ng/press

Kant, I. (2001). Critique of the Power of Judgment Edited by Guyer, P., translated by Guyer, P. and Matthews, E. Cambridge University Press

Magrane, E. (2012). Art and Environment. Institute of the Environment, University of Arizona, Tuscon, Arizona.

Markovic, S. (2012). Components of aesthetic experience: aesthetic fascination, aesthetic appraisal, and aesthetic emotion. Iperception 3(1): 1-17 published online doi:10.1068/i0450 ap PMCID:PMC 3485814

Mbahi A. A. (1992). Integrated Art and Cultural Programmes and Activities for
Schools in Nigeria, Creative Arts Department, University o Maiduguri, Borno State.

Oduwaye, L. (2006). Strategies of achieving orderly physical development in Lagos State. A Workshop Proceedings on Towards a Better Socio-Economic and Physical Socio-Economic and Physical Envirom of fagos State. Lagos; Areas of Lagos State. Lagos; Frontline Consultants, pp.64-81

Ognjenovic, P. (1997). Processing of aesthetic information. Epherical Studies of the Arts. 9: 1-9. Doi: 10.2190/KC25 -JWTN-NRX4-C7A1.

Oguntona, T. (1986). Basic Textiles: Design Concepts and Methods. Published by Ahmadu Bello University, zaria, Nigeria.

Plato, L. and Meskin, A. (2013). Unedited draft of entry on Aesthetic Value in Encyclopedia of Quality of Life Research Springer retrieved from internet on 15/01/19

Winston, A. S. and Cupchik, G. C. (2001). The elevation of high art and popular art by naïve and experienced viewers, Visual Art Research, 1-14 retrieved from internet on 15/01/19 